\title{
Antimicrobial activity and synergism of ursolic acid 3-O- $\alpha$-L-arabinopyranoside with oxacillin against methicillin-resistant Staphylococcus aureus
}

\author{
TIAN ZHOU ${ }^{1 *}$, ZHI LI $^{2 *}$, OK-HWA KANG ${ }^{1}$, SU-HYUN MUN ${ }^{1}, Y_{U N-S O O ~ S E O}{ }^{1}$, RYONG KONG $^{1}$, \\ DONG-WON SHIN ${ }^{3}$, XIANG-QIAN LIU ${ }^{2}$ and DONG-YEUL KWON ${ }^{1}$
}

\begin{abstract}
${ }^{1}$ Department of Oriental Pharmacy, College of Pharmacy and Wonkwang-Oriental Medicines Research Institute, Institute of Biotechnology, Wonkwang University, Iksan, Jeonbuk 570-749, Republic of Korea; ${ }^{2}$ School of Pharmacy, Hunan University of Chinese Medicine, Changsha, Hunan 410-208, P.R. China; ${ }^{3}$ Department of Oriental Medicine Resources, College of Bio Industry Science, Sunchon National University, Sunchon, Jeonnam 540-742, Republic of Korea
\end{abstract}

Received February 7, 2017; Accepted July 28, 2017

DOI: $10.3892 /$ ijmm.2017.3099

\begin{abstract}
The objective of the present study was to investigate the antibacterial activity of a single constituent, ursolic acid 3-O- $\alpha$-L-arabinopyranoside (URS), isolated from the leaves of Acanthopanax henryi (Oliv.) Harms, alone and in combination with oxacillin (OXA) against methicillin-resistant Staphylococcus aureus (MRSA). A broth microdilution assay was used to determine the minimal inhibitory concentration (MIC). The synergistic effects of URS and OXA were determined using a checkerboard dilution test and time-kill curve assay. The mechanism of action of URS against MRSA was analyzed using a viability assay in the presence of a detergent and an ATPase inhibitor. Morphological changes in the URS-treated MRSA strains were evaluated via transmission electron microscopy (TEM). In addition, the producing penicillin-binding protein $2 \mathrm{a}(\mathrm{PBP} 2 \mathrm{a})$ protein level was analyzed using western blotting. The MIC value of URS against MRSA was found to be $6.25 \mu \mathrm{g} / \mathrm{ml}$ and there was a partial synergistic effect between OXA and URS. The time-kill growth curves were suppressed by OXA combined with URS at a sub-inhibitory level. Compared to the optical density at $600 \mathrm{~nm}$ (OD600) value
\end{abstract}

Correspondence to: Professor Dong-Yeul Kwon, Department of Oriental Pharmacy, College of Pharmacy and Wonkwang-Oriental Medicines Research Institute, Institute of Biotechnology, Wonkwang University, Iksan, Jeonbuk 570-749, Republic of Korea

E-mail: sssimi@wku.ac.kr

Professor Xiang-Qian Liu, School of Pharmacy, Hunan University of Chinese Medicine, 300 Xueshi Road, Changsha, Hunan 410-208, P.R. China

E-mail:1xq0001cn@163.com

*Contributed equally

Key words: ursolic acid 3-O- $\alpha$-L-arabinopyranoside, oxacillin, methicillin-resistant Staphylococcus aureus, synergism, detergent, ATPase inhibitor, producing penicillin-binding protein $2 \mathrm{a}$ of URS alone $(0.09 \mu \mathrm{g} / \mathrm{ml})$, the OD600 values of the suspension in the presence of $0.09 \mu \mathrm{g} / \mathrm{ml}$ URS and $0.00001 \%$ Triton X-100 or $250 \mu \mathrm{g} / \mathrm{ml} \mathrm{N}, \mathrm{N}^{\prime}$-dicyclohexylcarbodiimide reduced by 56.6 and $85.9 \%$, respectively. The TEM images of MRSA indicated damage to the cell wall, broken cell membranes and cell lysis following treatment with URS and OXA. Finally, an inhibitory effect on the expression of PBP2a protein was observed when cells were treated with URS and OXA compared with untreated controls. The present study suggested that URS was significantly active against MRSA infections and revealed the potential of URS as an effective natural antibiotic.

\section{Introduction}

Staphylococcus aureus is a major bacterial pathogen that can cause severe infections in both the hospital and the community (1). This bacterium can cause many kinds of infection, including pneumonia, sepsis, wound sepsis, endocarditis, catheter-related infections and urinary tract infections $(2,3)$. Methicillin-resistant Staphylococcus aureus (MRSA) is a bacterium that is resistant to a variety of antibiotics, including $\beta$-lactams, aminoglycosides, quinolones, oxazolidinone, vancomycin and streptogramin type antibiotics (4). Infections caused by MRSA are a worldwide healthcare problem (5). Therefore, there is an urgent need for antibiotics to which MRSA is susceptible to further control the spread of illness caused by MRSA.

Antibiotic resistant MRSA is a significant challenge for all scientists who are involved in antibiotic drug discovery. One study suggested that combination drug treatment was an effective method to slow down or stop the development of drug-resistant bacteria (6). The mechanism of antibiotic activity against infections caused by Staphylococcus aureus (S. aureus) includes an interference with bacterial protein and nucleic acid synthesis, inhibition of metabolic pathways, disruption of the bacterial membrane structure and cell wall biosynthesis (7-9). By contrast, S. aureus strains become resistant to $\beta$-lactam antibiotics by producing penicillin-binding protein $2 \mathrm{a}(\mathrm{PBP} 2 \mathrm{a})$, a protein with lower binding affinity to $\beta$-lactams. In normal circumstances, $S$. aureus strains produce 
penicillin-binding proteins (PBPs) for synthesis of bacterial cell walls $(10,11)$. In resistant $S$. aureus strains, PBP2a replaces the function of normal PBPs.

Acanthopanax henryi (A. henryi) (Oliv.) Harms belongs to the Araliaceae family and may be used as a traditional oriental medicine for the treatment of rheumatism and inflammation $(12,13)$. Some studies have also reported that it has a strong antioxidant activity and improves the symptoms of Alzheimer's disease $(14,15)$. However, the antimicrobial activity of $A$. henryi (Oliv.) Harms has not been evaluated.

In the present study, the antibacterial effect of ursolic acid 3-O- $\alpha$-L-arabinopyranoside (URS) (Fig. 1), isolated from the leaves of A. henryi (Oliv.) Harms, against MRSA was investigated. To evaluate the anti-MRSA mechanisms of URS, the synergistic effect of URS combined with oxacillin (OXA), the anti-MRSA activity of URS combined with a membrane permeability agent and ATPase inhibitor, the morphological changes in bacterial cells and the levels of PBP2a production were evaluated.

\section{Materials and methods}

Plant materials. The leaves of A. henryi (Oliv.) Harms were collected in October 2012 in Xinhua, Changsha, China. The plant species was confirmed by Professor Xiang-Qian Liu (Hunan Key Laboratory of Traditional Chinese Medicine Modernization, Hunan University of Chinese Medicine, Changsha, China) and the voucher specimen (no. 20121125) was deposited at the School of Pharmacy, Hunan University of Chinese Medicine.

Extraction and isolation. The dried leaves of A. henryi (Oliv.) Harms $(10 \mathrm{~kg})$ were cut into small pieces, extracted three times with $\mathrm{MeOH}(3 \times 100 \mathrm{ml})$ at room temperature, and concentrated under reduced vacuum to obtain a dark-green residue $(0.8 \mathrm{~kg})$. The residue was then suspended in $\mathrm{H}_{2} \mathrm{O}$ and partitioned with petroleum ether. The water fraction was fractionated using column chromatography (CC) on macroporous resin and eluted with a gradient of $\mathrm{EtOH} / \mathrm{H}_{2} \mathrm{O}(0,30,50,75$ and $95 \%)$ into five fractions (1-5). Fraction 4 (75\% EtOH, $14.0 \mathrm{~g})$ was subjected to silica gel $\mathrm{CC}$ and eluted with $\mathrm{CHCl}_{3} / \mathrm{MeOH} / \mathrm{H}_{2} \mathrm{O}$ (25:1:0/1:1:0.2) to give fifteen fractions (A-O). Fraction $\mathrm{C}(119 \mathrm{mg})$ was re-fractionated on silica gel $\mathrm{H} \mathrm{CC}$ and eluted with $\mathrm{CHCl}_{3} / \mathrm{MeOH} / \mathrm{H}_{2} \mathrm{O}$ (15:1:0/6:1:0.1) to give six sub-fractions (C1-C6). Sub-fraction C3 $(106.0 \mathrm{mg}$ ) was subjected to ODS CC and eluted with a gradient of $\mathrm{MeOH} / \mathrm{H}_{2} \mathrm{O}$ (70, 80, 90 and $100 \%$ ) to yield $12.0 \mathrm{mg}$ URS (16).

The compound structures were identified using mass spectroscopy, 1D-nuclear magnetic resonance (NMR) and 2D-NMR and the spectral data were compared with those reported previously (16). ${ }^{1} \mathrm{H}$ NMR and ${ }^{13} \mathrm{C}$ NMR spectra were measured on a Varian INOVA $400 \mathrm{M}$ spectrometer (Agilent Technologies, Inc., Santa Clara, CA, USA) with chemical shifts reported as ppm (tetramethylsilane as internal standard). Electrospray ionization mass spectra were then measured using an Agilent 6530 Accurate-Mass Q-TOF (Agilent Technologies, Inc.).

High performance liquid chromatography (HPLC). The purity of URS was $>98 \%$, as determined via HPLC as previously described (17). Briefly, URS was dissolved in $\mathrm{MeOH}$ to a concentration of $0.1 \mathrm{mg} / \mathrm{ml}$ for HPLC analysis by using a
Kinetex XB-C18 analytical column (100x4.6 mm x2.6 $\mu \mathrm{m}$; Phenomenex, Inc., Torrance, CA, USA) at $30^{\circ} \mathrm{C}$. Elution was conducted using mobile phase $\mathrm{A}$ (water) and mobile phase $\mathrm{B}$ (acetonitrile) with a gradient as follows: 0-2 $\mathrm{min}, 29-31 \% \mathrm{~B}$; 2-13 min, 31-35\% B; 13-15 min, 35-40\% B; 15-23 min, $40-44 \% \mathrm{~B} ; 23-25 \mathrm{~min}, 44-46 \% \mathrm{~B} ; 25-31 \mathrm{~min}, 46-49 \% \mathrm{~B}$; and $31-38 \mathrm{~min}, 49-55 \% \mathrm{~B}$. The flow rate was constant at $1.0 \mathrm{ml} / \mathrm{min}$ and the effluents were monitored at $210 \mathrm{~nm}$ using an Agilent 1200 HPLC system with variable wavelength detector (Agilent Technologies, Inc.). The purity value was found to be $>98 \%$ using a peak area normalization method. The purity value was obtained by calculating the percentage of the URS peak area to that of the total peaks in the HPLC chromatogram.

Bacterial strains and culture medium. Among the eight strains of S. aureus used in the present study, two clinical MRSA isolates, DPS-1 and DPS-2, as the references $(18,19)$ mentioned, were collected from two different patients at Wonkwang University Hospital (Iksan, Korea); two strains were MRSA ATCC 33591 and methicillin-susceptible S. aureus (MSSA) ATCC 25923, purchased from the American Type Culture Collection (Manassas, VA, USA); and the remaining four MRSA strains, CCARM 3090, CCARM 3091, CCARM 3095, CCARM 3102, were provided by the Culture Collection of Antimicrobial Resistant Microbes (National Research Resource Bank, Seoul, Korea). All bacteria were cultured on either Mueller-Hinton agar (MHA) or Brain Heart Infusion agar at $37^{\circ} \mathrm{C}$ for $24 \mathrm{~h}$. The bacterial strains were suspended in either Mueller-Hinton broth (MHB) or brain heart infusion broth (BHIB) and grown at $37^{\circ} \mathrm{C}$ for $24 \mathrm{~h}$ in order to perform the experiments. The bacteria were stored in $30 \%$ glycerol and frozen at $-80^{\circ} \mathrm{C}$.

Materials and reagents. Difco ${ }^{\mathrm{TM}}$ Mueller-Hinton agar, Difco $^{\mathrm{TM}}$ Mueller-Hinton broth, Difco ${ }^{\mathrm{TM}}$ brain heart infusion agar, Bacto $^{\mathrm{TM}}$ Brain Heart Infusion broth and Difco ${ }^{\mathrm{TM}}$ skim milk were obtained from Difco Laboratories (Baltimore, MD, USA). Glycerol was obtained from Sigma-Aldrich; Merck KGaA (Darmstadt, Germany). MTT, Triton X-100 (TX-100), N,N'-dicyclohexylcarbodiimide (DCCD), paraformaldehyde, glutaraldehyde, sodium cacodylate buffer, osmium tetroxide, uranyl acetate, $\mathrm{EtOH}, \mathrm{MeOH}$, propylene oxide, Spurr's resin, OXA and solvents were purchased from Sigma-Aldrich; Merck KGaA. SMART ${ }^{\mathrm{TM}}$ bacterial protein extraction solution was purchased from Intron Biotechnology, Inc. (Seongnam, Korea). The chemiluminescent ECL assay kit was purchased from ATTO Corp. (Tokyo, Japan).

Determination of the minimal inhibitory concentration (MIC). A total of 8 bacterial strains were subjected to antimicrobial susceptibility and MIC assays. The MIC values of URS and the antibiotic, OXA, against MRSA and MSSA were determined via broth microdilution assay using a 96-well microplate, according to a previous study (19). A series of 2-fold dilutions of URS in MHB and BHIB were prepared and the bacteria colonies were picked with a $1 \mu 1$ white sterile loop and needle to be suspended in either MHB or BHIB. The inocula were adjusted to the 0.5 of the McFarland standard scale $\left[\sim 1.5 \times 10^{8}\right.$ colony-forming units $\left.(\mathrm{CFU}) / \mathrm{ml}\right]$ and the final inocula were adjusted to $1.5 \times 10^{5} \mathrm{CFU} /$ spot. The inoculated broth was incubated at $37^{\circ} \mathrm{C}$ for $24 \mathrm{~h}$ and the MIC was determined using 


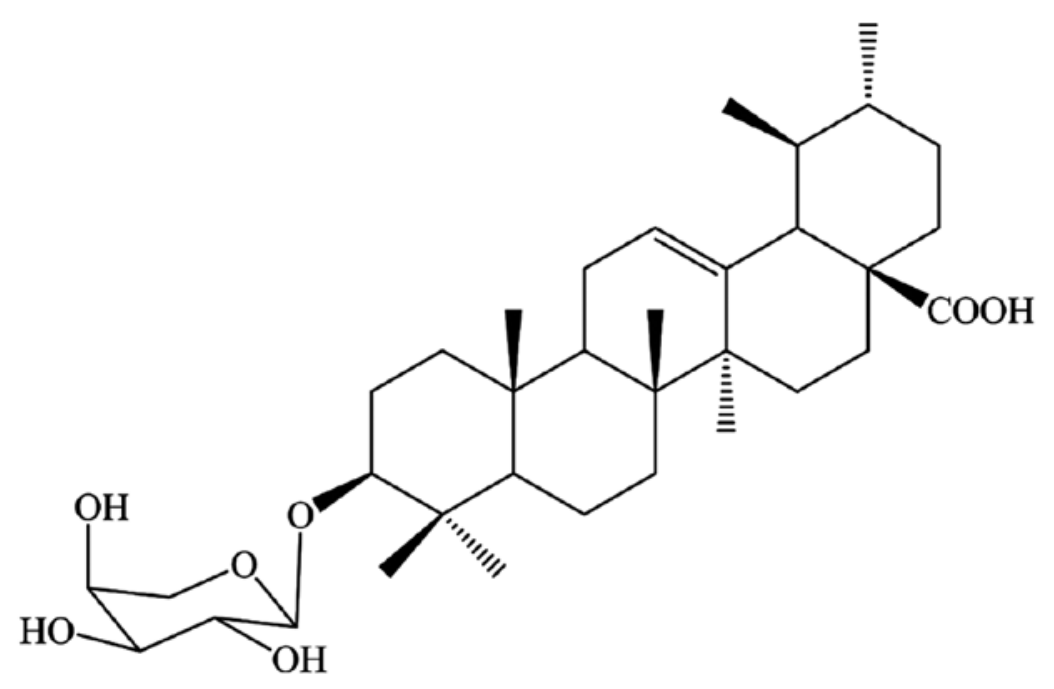

Figure 1. The chemical structure of ursolic acid 3-O- $\alpha$-L-arabinopyranoside.

MTT reagent. Following the $24 \mathrm{~h}$ incubation, MTT $(1 \mathrm{mg} / \mathrm{ml})$ was added to the broth suspension in every well and the plate was incubated for $30 \mathrm{~min}$ in a $37^{\circ} \mathrm{C}$ incubator. Blue color indicated the presence of bacteria $(18,20)$. The MIC was defined as the lowest concentration that inhibited bacterial growth.

Checkerboard dilution test. The synergistic effect between URS and OXA was determined using a checkerboard dilution test (21). Serial dilutions of URS with different concentrations OXA were mixed in cation-supplemented MHB and BHIB. Each test strain of the final inocula concentration was adjusted to $1.5 \times 10^{5} \mathrm{CFU} / \mathrm{ml}$ and incubated at $37^{\circ} \mathrm{C}$ for $24 \mathrm{~h}$. For the synergy studies, the range of concentrations used was determined according to the previously determined MIC of OXA for each specific isolate. The concentration of URS ranged from 6.25 to $0.19 \mu \mathrm{g} / \mathrm{ml}$. Following a $24 \mathrm{~h}$ incubation, the MICs were interpreted. The in vitro interaction between the drugs was quantified by determining the fractional inhibitory concentration (FIC). The FIC of each agent was calculated as the MIC of the agents in combination, divided by the MIC of the agent alone. The FIC index (FICI) was calculated using the following formula: $\mathrm{FICI}=\mathrm{FIC}_{\mathrm{A}}+\mathrm{FIC}_{\mathrm{B}}=[\mathrm{A}] / \mathrm{MIC}_{\mathrm{A}}+[\mathrm{B}] / \mathrm{MIC}_{\mathrm{B}}$, where $[\mathrm{A}]$ and $[\mathrm{B}]$ were the concentrations of $\operatorname{drug} \mathrm{A}$ and $\mathrm{B}$, respectively, and $\mathrm{MIC}_{\mathrm{A}} / \mathrm{FIC}_{\mathrm{A}}$ and $\mathrm{MIC}_{\mathrm{B}} / \mathrm{FIC}_{\mathrm{B}}$ were the $\mathrm{MIC} / \mathrm{FIC}$ of drug A and $\mathrm{B}$, respectively. The FICI was interpreted as follows: $<0.5$, synergy; 0.5-0.75, partial synergy; $0.75-1$, additive effect; $1-4$, no effect; and $>4$, antagonism. Finally, the different values of synergy between the two agents were calculated (22).

Time-kill assay. The synergistic antimicrobial effect was determined using a time-kill assay, as described previously (23). URS combined with OXA, OXA alone and URS alone were compared to control (drug-free) regarding the synergistic effect on the bacterial growth curve (24). At five different time phases $(0,4,8,16$ and $24 \mathrm{~h})$, bacterial growth curves were observed. Bacterial cultures were diluted with fresh $\mathrm{MHB}$ to $\sim 1.5 \times 10^{5} \mathrm{CFU} / \mathrm{ml}$ and the bacteria suspensions were incubated at $37^{\circ} \mathrm{C}$ for $24 \mathrm{~h}$. Aliquots $(0.1 \mathrm{ml})$ of the suspension were taken at $0,4,8,16$ and $24 \mathrm{~h}$ of incubation and serial 10 -fold dilutions were prepared in saline as needed. Following incubation for $24 \mathrm{~h}$, the number of viable cells was determined on a drug-free MHA plate. Colony counts were performed on plates and 30-300 colonies were calculated. The lower limit of sensitivity of the colony counts was $100 \mathrm{CFU} / \mathrm{ml}$. The antimicrobial agents used were considered bactericidal at the lowest concentration that reduced the original inoculum by $3 \log _{10} \mathrm{CFU} / \mathrm{ml}(99.9 \%)$ for each of the indicated times. However, they were designated bacteriostatic if the inoculum was reduced by $0-3 \log _{10} \mathrm{CFU} / \mathrm{ml}$.

Effect of URS on membrane-permeabilizing agents and ATPase inhibitors. To explore whether the antibacterial activity of URS was associated with the altered membrane permeability or the action of ATPase, the authors evaluated the antibacterial activity of URS in the presence of a detergent and an ATPase-inhibiting agent (19). To determine the detergent-induced permeabilization, an appropriate concentration of URS was determined using the detergent TX-100 (25), which significantly increases bacterial sensitivity to antibiotics (26). DCCD, a metabolic inhibitor that can decrease ATP levels by disrupting electrochemical proton gradients in a bacterial environment, was used as an inhibitor of ATPase $(19,27)$. The bacteria culture were adjusted to $1.5 \times 10^{5} \mathrm{CFU} / \mathrm{ml}$ and $100 \mu \mathrm{l} /$ well was added to 96 -well microplate. A total density of $10 \mu \mathrm{l} /$ well of URS, at a concentration of 1/64 MIC, with the presence of $0.00001 \% \mathrm{TX}-100$ and $250 \mu \mathrm{g} / \mathrm{ml}$ DCCD were individually added to the 96-well microplate and incubated at $37^{\circ} \mathrm{C}$ for $24 \mathrm{~h}$. The results were read at optical density $600 \mathrm{~nm}$.

Transmission electron microscopy (TEM). On the basis of biological activity, morphological changes in MRSA ATCC 33591 following the addition of URS were evaluated using TEM, according to a previously described protocol with some modifications $(28,29)$. MRSA exponential phase cultures were prepared by diluting cultures in $\mathrm{MHB}$ overnight and cell growth was continued at $37^{\circ} \mathrm{C}$ until the cultures reached the mid-logarithmic phase of growth. The MHB-grown exponential-phase MRSA was treated with $31.25 \mu \mathrm{g} / \mathrm{ml}$ OXA alone, $1 / 2 \mathrm{MIC}$ of URS alone, and $31.25 \mu \mathrm{g} / \mathrm{ml} \mathrm{OXA} \mathrm{+} \mathrm{1/2} \mathrm{MIC}$ 
of URS for $4 \mathrm{~h}$. Following treatment, $2 \mathrm{ml}$ of the culture was collected by centrifugation at $10,000 \mathrm{x}$ g for $10 \mathrm{~min}$. Following the removal of the supernatant, pellets were washed with $\mathrm{MHB}$ and primary fixed with $2 \%$ paraformaldehyde and $2 \%$ glutaraldehyde at $4^{\circ} \mathrm{C}$ for $2 \mathrm{~h}$. Samples were washed and resuspended thrice in $0.05 \mathrm{M}$ sodium cacodylate buffer $\left(\mathrm{pH} \mathrm{7.2)}\right.$ at $4^{\circ} \mathrm{C}$ for $10 \mathrm{~min}$, then post-fixed with $1 \% \mathrm{OsO}_{4}$ at $4^{\circ} \mathrm{C}$ for $2 \mathrm{~h}$. The samples were then washed twice with steriledistilled water at room temperature. Thereafter, the samples were en bloc stained with $0.5 \%$ uranyl acetate at $4^{\circ} \mathrm{C}$ for $30 \mathrm{~min}$ and dehydrated using a graded $\mathrm{EtOH}$ series. Finally, $100 \%$ propylene oxide was used for transit and infiltration with propylene oxide and Spurr's resin reagents in a specific ratio. The specimens were examined using an energy-filtering transmission electron microscope (LIBRA 120; Carl Zeiss GmbH, Oberkochen, Germany) operated at an accelerating voltage of $120 \mathrm{kV}$. Transmitted electron signals were recorded using a 4x4 k slow-scan charge-coupled device camera (Ultrascan 4000 SP; Gatan, Pleasanton, CA, USA) attached to an electron microscope.

Western blotting. The western blot assay was performed according to the standard procedures to measure the translated protein level $(30,31)$. The MRSA culture (ATCC 33591) was grown at an OD600 of 0.4 in MHB and treated with various concentrations and combinations of OXA and URS for $4 \mathrm{~h}$ for western blot analysis (32). Briefly, cells were harvested and suspended in SMART ${ }^{\mathrm{TM}}$ bacterial protein extraction solution containing Tris- $\mathrm{HCl}(\mathrm{pH} 7.5)$. The extraction was performed according to the manufacturer's protocol. Protein concentrations were measured using the Bio-Rad protein assay reagent (Bio-Rad Laboratories, Inc., Hercules, CA, USA) and cell lysates were separated using $10 \%$ sodium dodecyl sulfate-polyacrylamide gel electrophoresis (SDS-PAGE). The electrophoresed gels were transferred to Amersham ${ }^{\mathrm{TM}}$ Hybond $^{\mathrm{TM}}$-P-membranes (GE Healthcare Life Sciences, Chalfont, UK). The membranes were blocked with $5 \%$ skim milk for $1 \mathrm{~h}$ and hybridized with monoclonal mouse anti-PBP2a primary antibody (1:500, cat. no. 70PB001; DiNonA Inc., Seoul, Korea) overnight at $4^{\circ} \mathrm{C}$. Loading differences were normalized with monoclonal anti-glyceraldehyde 3-phosphate dehydrogenase (GAPDH) antibody (1:500, cat. no. sc-166574, Santa Cruz Biotechnology, Inc., Dallas, TX, USA). Following incubation with anti-mouse IgG secondary antibody $(1: 1,000$, cat. no. G-21040; Enzo Life Sciences, Ann Arbor, MI, USA) at room temperature for $1 \mathrm{~h}$, immunoreactive proteins were detected using a chemiluminescent ECL assay kit (ATTO Corp.) according to the manufacturer's instructions. Western blot bands were visualized using ImageQuant LAS 4000 Mini Luminescent image analyzer (GE Healthcare Life Sciences) and the quantitative measurement of band intensity was performed using ImageJ software (version 1.45S; National Institutes of Health, Bethesda, MA, USA)

Statistical analysis. Analyses were performed in triplicate and data were presented as the mean \pm standard deviation. Results were statistically analyzed using an independent Scheffe's t-test (SPSS software version 22.0; IBM SPSS, Armonk, NY, USA). $\mathrm{P}<0.05$ was considered to indicate a statistically significant difference.
Table I. MIC values of URS and OXA against MSSA and MRSA.

\begin{tabular}{llc}
\hline & \multicolumn{2}{c}{ MIC $(\mu \mathrm{g} / \mathrm{ml})$} \\
\cline { 2 - 3 } S. aureus strains & URS & OXA \\
\hline ATCC 25923 & 3.125 & $<0.97$ \\
ATCC 33591 & 6.25 & 62.5 \\
CCARM 3090 & 6.25 & 500 \\
CCARM 3091 & 6.25 & 2000 \\
CCARM 3095 & 6.25 & 500 \\
CCARM 3102 & 6.25 & 500 \\
DPS-1 & 6.25 & 500 \\
DPS-2 & 6.25 & 3.9
\end{tabular}

DPS, Staphylococcal strains from the Department of Plastic Surgery, Wonkwang University Hospital; MIC, minimal inhibitory concentration; MRSA, methicillin-resistant Staphylococcus aureus; MSSA, methicillin-susceptible Staphylococcus aureus; OXA, oxacillin; URS, ursolic acid 3-O- $\alpha$-L-arabinopyranoside; S. aureus, Staphylococcus aureus. Values represent triplicates of three independent experiments.

\section{Results}

Antimicrobial activity of URS and antibiotics. Antimicrobial susceptibility studies were performed using a broth microdilution method. The MIC values of URS and OXA against eight strains of $S$. aureus are presented in Table I. The data indicated that URS, which was isolated from the leaves of $A$. henryi (Oliv.) Harms, had high antimicrobial activity against MRSA and MSSA. The MIC values of URS against MSSA and MRSA were 3.125 and $6.25 \mu \mathrm{g} / \mathrm{ml}$, respectively. The MIC of OXA against MSSA was $<0.97 \mu \mathrm{g} / \mathrm{ml}$, whereas the MIC against MRSA ranged from 3.9 to $2,000 \mu \mathrm{g} / \mathrm{ml}$. The high MIC values of OXA against MRSA confirmed that the studied strains were resistant to OXA, whereas the MIC value of OXA against MSSA indicated the susceptibility of this strain to the antibiotic (11).

Synergistic effects of URS and OXA based on FICI. Evaluation of the synergistic effect of URS and OXA in combination against MRSA was performed using a checkerboard dilution method. The results are presented in Table II and suggested that in the presence of URS, the susceptibility of MRSA to OXA increased. Treatment with 1/2 MIC URS in combination with OXA reduced the MIC of OXA by 2-32-fold.

Time-kill curve assay. On the basis of FIC indices, the synergism of URS and OXA against MRSA was confirmed using a time-kill assay. In the present study, two strains, CCARM 3090 and DPS-1, were used to perform the analysis. The results are reported in Fig. 2. The time-kill curves were constructed with control, 1/2 MIC OXA alone, 1/2 MIC URS alone, 1/2 MIC OXA and 1/2 MIC URS in combination, and 1/2 MIC OXA and 3/4 MIC URS in combination at time-points $0,4,8,16$ and $24 \mathrm{~h}$. The results are presented as the $\log$ value of the number of surviving bacteria in the antimicrobial test at the different time intervals. As the figures indicated, at $24 \mathrm{~h}$, treatment with 

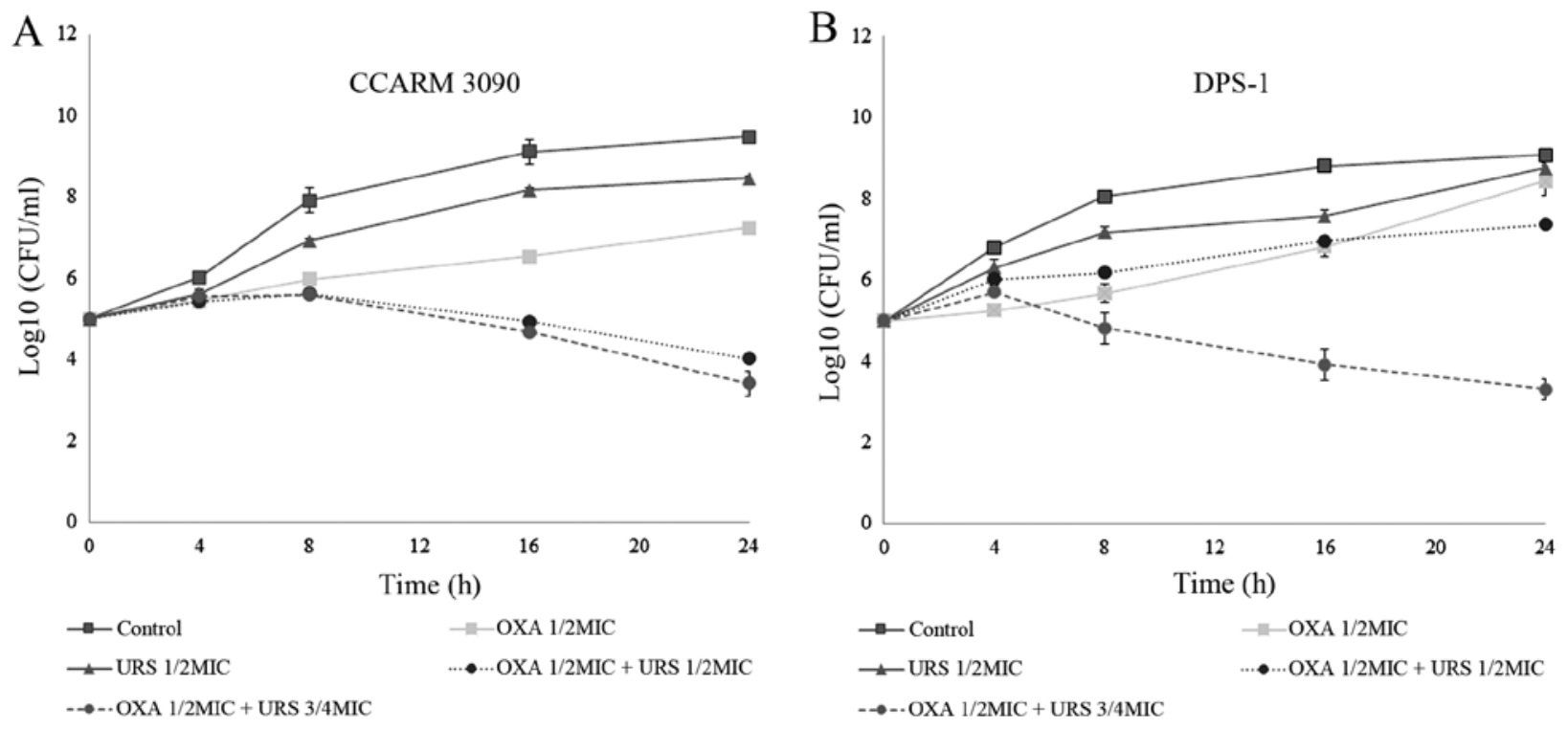

Figure 2. (A) Time-kill curve of sub-inhibitory concentrations of OXA alone, URS alone, and OXA and URS in combination against MRSA CCARM 3090. (B) Time-kill curve of sub-inhibitory concentration of OXA alone, URS alone, and OXA and URS in combination against MRSA DPS-1. The untreated was the control. The time-kill assay was performed thrice and the data are represented as the mean \pm standard deviation. OXA, oxacillin; URS, ursolic acid 3-O- $\alpha$-L-arabinopyranoside; MRSA, methicillin-resistant Staphylococcus aureus; CFU, colony-forming units.

Table II. Results of the combination of URS and OXA against MRSA strains.

\begin{tabular}{lccccc}
\hline & & \multicolumn{2}{c}{ MIC $(\mu \mathrm{g} / \mathrm{ml})$} & & \\
\cline { 3 - 4 } Strains & Agent & Alone & Combination & FICI & Outcome \\
\hline ATCC 33591 & URS & 6.25 & 1.56 & 0.75 & Partial S. \\
& OXA & 62.5 & 31.25 & & \\
CCARM 3090 & URS & 6.25 & 3.125 & 0.53 & Partial S. \\
& OXA & 500 & 15.6 & & \\
CCARM 30955 & URS & 6.25 & 3.125 & 0.56 & Partial S. \\
& OXA & 500 & 31.25 & & \\
CCARM 3102 & URS & 6.25 & 3.125 & 0.56 & Partial S. \\
& OXA & 500 & 31.25 & & \\
DPS-1 & URS & 6.25 & 0.19 & 0.53 & Partial S. \\
& OXA & 500 & 250 & & \\
DPS-2 & URS & 6.25 & 1.56 & 0.75 & Partial S. \\
& OXA & 3.9 & 1.95 & & \\
\hline
\end{tabular}

Values represent triplicates of three independent experiments. DPS, Staphylococcal strains from the Department of Plastic Surgery, Wonkwang University Hospital; FICI, fractional inhibitory concentration index; MIC, minimal inhibitory concentration; Partial S., partial synergy; MRSA, methicillin-resistant Staphylococcus aureus; MSSA, methicillin-susceptible $S$. aureus; OXA, oxacillin; URS, ursolic acid 3-O- $\alpha$-L-arabinopyranoside. index interpretation, $<0.5$, synergy; 0.5-0.75, partial synergy; $0.75-1$, additive effect; $1-4$, no effect; and $>4$, antagonism.

1/2 MIC OXA and 3/4 MIC URS in combination resulted in combined group bacteria counts that decreased to $3 \log _{10}$. However, the original antibacterial-free control count was
$1.5 \times 10^{5} \mathrm{CFU} / \mathrm{ml}$, which increased to almost $10^{10} \mathrm{CFU} / \mathrm{ml}$ after $24 \mathrm{~h}$ (33). In addition, the time-kill curves indicated a concentration-dependent bactericidal effect against MRSA strains.

Antimicrobial activity with detergents and ATPase inhibitors. MRSA CCARM 3090 was used to investigate the effects of enhanced membrane permeability by using detergents and the diversification of susceptibility by using ATPase inhibitors on the activity of URS. The results are presented in Fig. 3. The membrane-permeabilizing agent, TX-100, can increase the permeability of the outer membrane in gram-negative bacteria (34). Compared to the OD600 value of URS alone (1/64 MIC), the OD600 value of the suspension in the presence of 1/64 MIC URS and $0.00001 \%$ TX-100 was reduced $56.6 \%$. From the results of the OD600 values, in the presence of either URS alone (1/64 MIC) or $250 \mu \mathrm{g} / \mathrm{ml}$ DCCD alone, MRSA maintained its viability. However, the OD600 value of the suspension significantly decreased by URS in combination with DCCD. Bacterial viability in the presence of 1/64 MIC URS and $250 \mu \mathrm{g} / \mathrm{ml}$ DCCD reduced to $11.7 \%$.

Effect on bacterial cell morphology. To determine morphological changes, MRSA ATCC 33591 treated with OXA $(31.25 \mu \mathrm{g} / \mathrm{ml})$ alone, URS $(3.125 \mu \mathrm{g} / \mathrm{ml})$ alone, and OXA and URS in combination was examined by TEM analysis. The results are indicated in Fig. 4. The images indicated characteristic morphological changes in the cells of MRSA ATCC 33591 after treatment with OXA and URS. The untreated bacterial cells had normal morphology with distinct septa (Fig. 4A). In the presence of OXA and URS individually, the cytoplasmic membranes of the bacterial cells were damaged and had rougher surfaces (Fig. 4B and C) compared to those of control cells. Following exposing MRSA to the combination of OXA and URS, deformation of bacterial cells was observed compared to groups treated with OXA alone and URS 

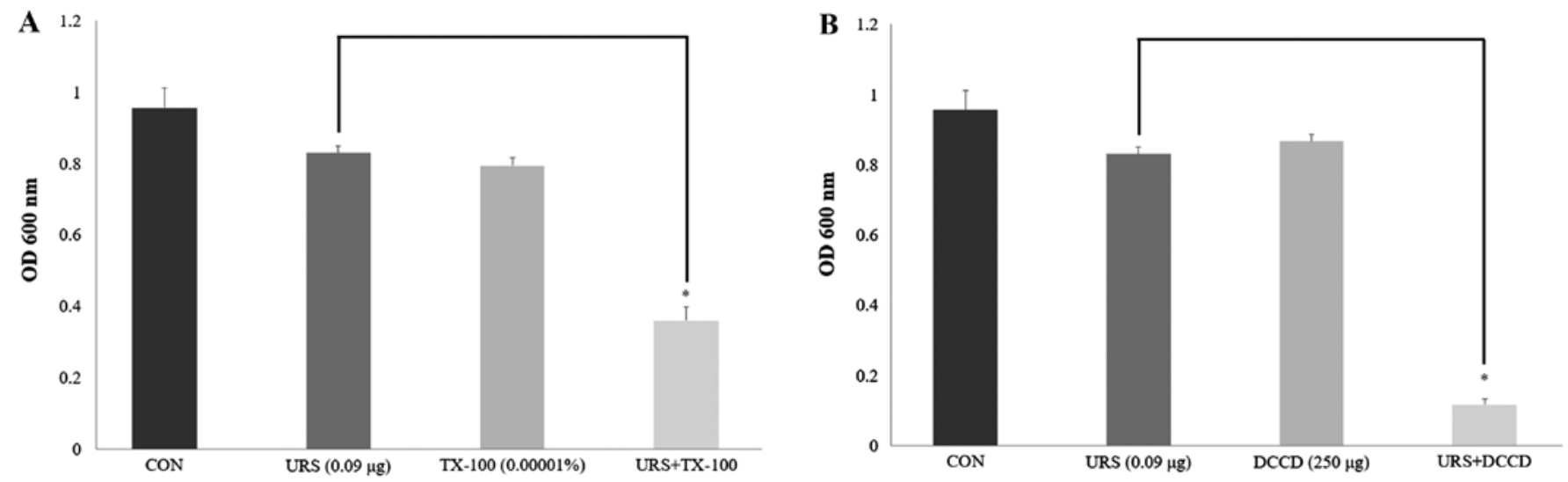

Figure 3. (A) The effect of the membrane-permeabilizing agent, TX-100, on the susceptibility of methicillin-resistant Staphylococcus aureus CCARM 3090 to URS treatment. (B) The effect of the ATPase-inhibitor, DCCD, on the susceptibility of MRSA CCARM 3090 to URS treatment. The viability of bacteria was determined via spectrophotometry (optical density at $600 \mathrm{~nm}$, OD600) following incubation for $24 \mathrm{~h}$ with $0.09 \mu \mathrm{g} / \mathrm{ml} \mathrm{URS}$ and $0.00001 \% \mathrm{TX}-100 \mathrm{and} 0.09 \mu \mathrm{g} / \mathrm{ml}$ URS and $250 \mu \mathrm{g} / \mathrm{ml}$ DCCD. These data are represented as the mean \pm standard deviation of three independent experiments. ${ }^{*} \mathrm{P}<0.05$ as indicated. CON, control S. aureus strain, which was not treated; TX-100, Triton X-100; URS, ursolic acid 3-O- $\alpha$-L-arabinopyranoside; DCCD, N,N'-dicyclohexylcarbodiimide; MRSA, methicillin-resistant Staphylococcus aureus.
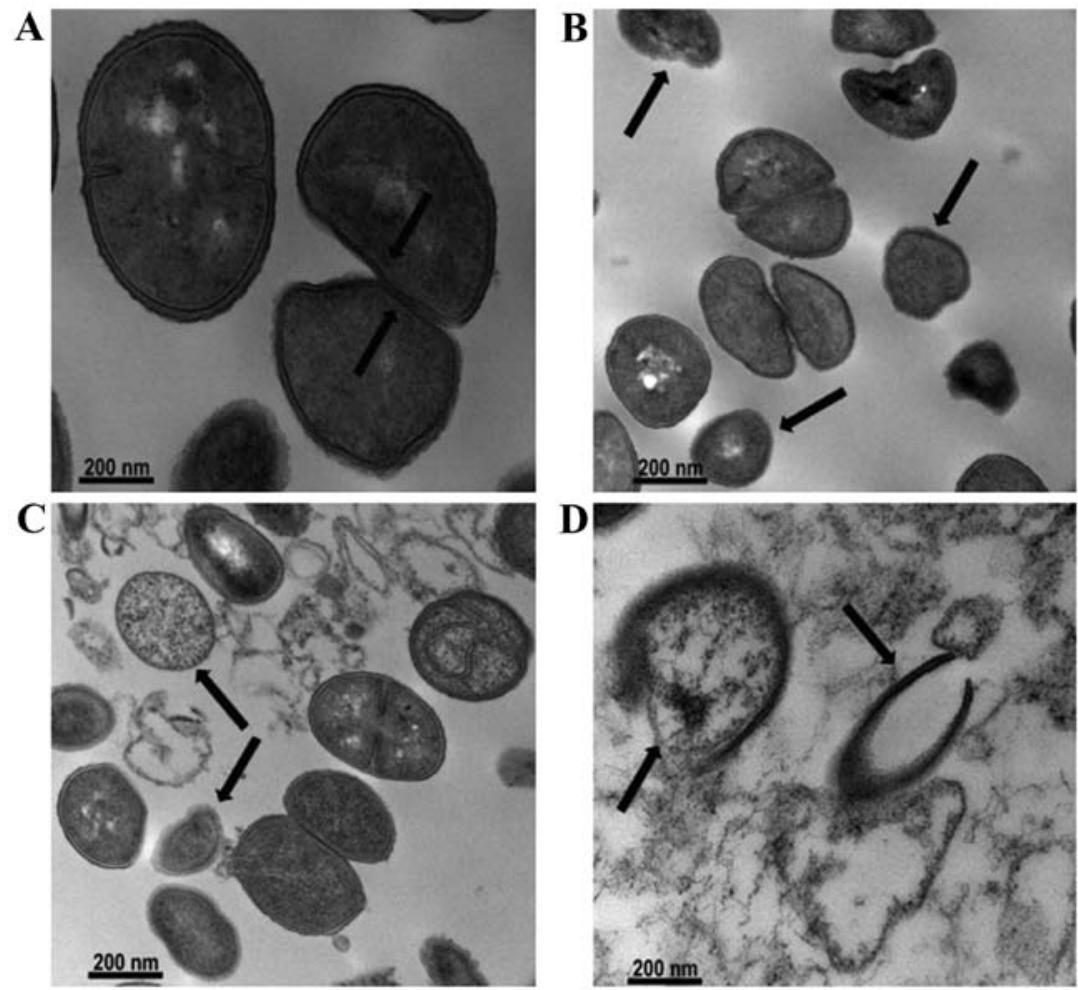

Figure 4. (A-D) Transmission electron microscopy images of MRSA following $24 \mathrm{~h}$ of URS and OXA treatment at various concentrations. (A) Untreated control MRSA. These arrows indicate intact septa. (B) MRSA treated with $1 / 2 \mathrm{MIC}$ of OXA $(31.25 \mu \mathrm{g} / \mathrm{ml})$. These arrows indicate damage of cytoplasmic membrane. (C) MRSA treated with $1 / 2$ MIC of URS (3.125 $\mu \mathrm{g} / \mathrm{ml})$. These arrows indicate damage to the cytoplasmic membrane. (D) MRSA treated with the $1 / 2$ MIC of OXA $(31.25 \mu \mathrm{g} / \mathrm{ml})$ and $1 / 2$ MIC of URS $(3.125 \mu \mathrm{g} / \mathrm{ml})$. These arrows indicate cell membrane disintegration and dispersion of intracellular contents after exposure to URS combined with OXA. MRSA, methicillin-resistant Staphylococcus aureus; OXA, oxacillin; MIC, minimal inhibitory concentration; URS, ursolic acid 3-O- $\alpha$-L-arabinopyranoside.

alone (Fig. 4D). This caused cell membrane disintegration, cell lysis and release of cytoplasmic contents. In addition, the cells appeared almost absent. This suggested a strong bactericidal activity against MRSA. The notable changes in bacterial cell morphology indicated that bacterial cell membrane viscosity and permeability were compromised by treatment with the combination of URS and OXA (24).
Expression of PBP2a protein in MRSA. To detect the protein level of PBP2a in MRSA, western blotting was performed. PBP2a expression levels following the tested treatments are summarized in Fig. 5. GAPDH, which served as an internal control, was detected after all treatments (results not shown). The experimental samples consisted of control, OXA $(31.25 \mu \mathrm{g} / \mathrm{ml})$, URS $(6.25 \mu \mathrm{g} / \mathrm{ml})$ and the combination of OXA 


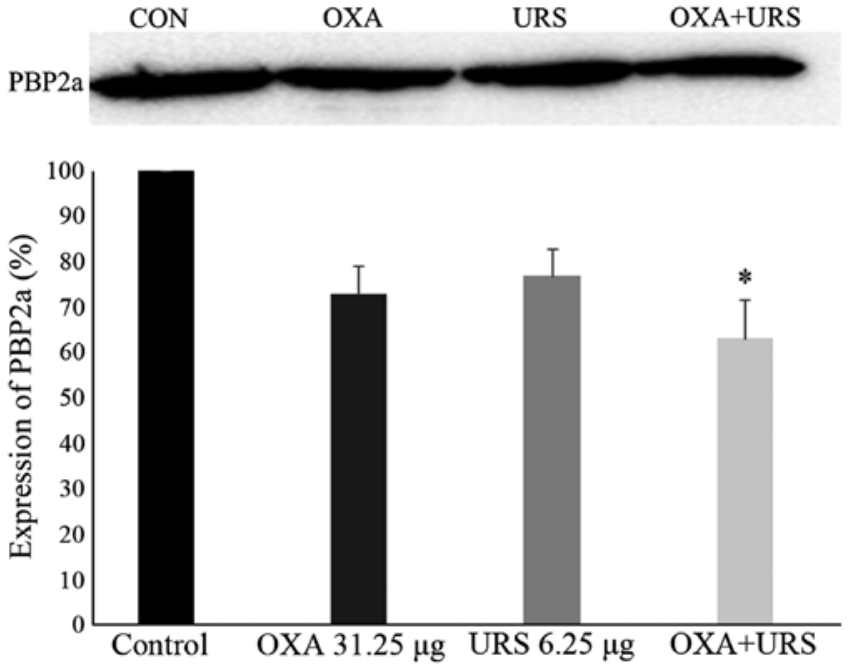

Figure 5. Expression of PBP2a in MRSA cultures grown in the presence of sub-inhibitory concentrations of URS and OXA. Western blotting image, lane 1, control MRSA; lane 2, OXA $31.25 \mu \mathrm{g} / \mathrm{ml}$; lane 3, URS $6.25 \mu \mathrm{g} / \mathrm{ml}$, lane 4, the combination of URS and OXA. Quantitative densitometric analysis of PBP2a expression in MRSA cultures grown in the presence of OXA alone, URS alone, and OXA and URS in combination, normalized to GAPDH loading control. These data are represented as the means \pm standard deviation of 3 independent experiments. ${ }^{*} \mathrm{P}<0.05$ vs. control. PBP $2 a$, penicillin-binding protein 2a; MRSA, methicillin-resistant Staphylococcus aureus; OXA, oxacillin; URS, ursolic acid 3-O- $\alpha$-L-arabinopyranoside.

(31.25 $\mu \mathrm{g} / \mathrm{ml})$ and URS $(6.25 \mu \mathrm{g} / \mathrm{ml})$. As the figure demonstrated, PBP2a was not completely inhibited; however, the PBP2a protein level decreased non-significantly on the addition of URS and OXA alone. Compared to control, the expression of PBP2a of the combination group was reduced $36.98 \%$. The decrease in the PBP2a level may indicate that URS interrupted the process of protein synthesis by damaging RNA.

\section{Discussion}

MRSA, a gram-positive bacterial pathogen, can cause infections in a wide range of human tissues. Because MRSA acquires resistance to most antibiotics, few new drugs are available to treat it (35). The increasing emergence of multidrug-resistant bacteria is a worldwide healthcare problem. Therefore, new effective antimicrobial agents or novel therapeutic approaches for the treatment of infectious diseases caused by drug-resistant bacteria, including MRSA, are clearly needed. Previously, to control pathogenic microorganisms, there has been considerable interest in traditional Chinese medicine natural products isolated from herbal medicines for use as alternative treatments $(7,23)$. Some researchers reported that an effective strategy to conquer resistance mechanisms was the use of drug combinations, such as $\beta$-lactams together with $\beta$-lactamase inhibitors (36). In the present study, the authors demonstrated the synergism and mechanism of action of URS, obtained from the leaves of A. henryi (Oliv.) Harms, combined with OXA against MRSA.

In the present study, the MIC values of URS and OXA were determined using broth microdilution assay. The MICs of URS against MRSA and MSSA were 6.25 and $3.125 \mu \mathrm{g} / \mathrm{ml}$, respectively (Table I). These results indicated strong antibacterial activity against MRSA and MSSA. The low MIC exhibited by URS is very rare in natural products. The synergistic effects of URS and OXA were analyzed using a checkerboard dilution method, which indicated a partial synergistic effect between URS and OXA in various MRSA strains (Table II). When in the presence of URS at sub-inhibitory concentrations, the MIC of OXA was reduced by as much as 32-fold, from 500 to $15.6 \mu \mathrm{g} /$ $\mathrm{ml}$. This also indicated that URS restored the susceptibility of MRSA to OXA (11). Combination therapy is an urgently recommended empirical treatment for bacterial infections and for preventing the emergence of resistant mutant strains of bacteria $(37,38)$. The time-kill growth curves further confirmed the synergism between URS and OXA at sub-inhibitory concentrations (Fig. 2). Treatment with the combination of 3/4 MIC URS and 1/2 MIC OXA inhibited the growth of MRSA compared to MRSA strains that were treated with either URS or OXA alone. In addition, bacterial growth was suppressed after $8 \mathrm{~h}$ with this combination, but a total kill was not achieved. At the beginning of the exponential phase, the control with a rapidly growing and the combination group had same tendency. But the combination group with a slight bacterial growth compared to the control at exponential phase. An extended lag phase was observed compared to control. The lag phase is a special stage when bacteria equilibrate to adapt to a new environment by undergoing macromolecular repair and synthesis of cellular growth through DNA replication. Therefore, we inferred that the lengthy lag phase observed in our study was due to the inhibition of DNA replication, which delayed the cellular growth process $(11,39)$.

The reagents, TX-100 and DCCD, were used in combination with URS to detect the effects on bacterial cell viability. The results indicated that the OD600 values of the suspension were reduced by the combination of $0.09 \mu \mathrm{g} / \mathrm{ml}$ URS with $0.00001 \%$ TX-100 or $250 \mu \mathrm{g} / \mathrm{ml} \mathrm{DCCD} \mathrm{(Fig.} \mathrm{3).} \mathrm{TX-100} \mathrm{has}$ been reported to enhance cell membrane permeability, decrease methicillin resistance, and stimulate cell autolysis (28). DCCD, an inhibitor of ATPase, inhibited the $\mathrm{H}^{+}$translocation activity of the $\mathrm{F}_{0}$ domain of $\mathrm{F}_{0} \mathrm{~F}_{1}$-ATPase $(7,19)$. In the presence of detergent or an ATPase inhibitor, the susceptibility of MRSA to URS was increased. Consequently, the authors inferred that the antibacterial activity of URS was associated with cytoplasmic membrane permeability and inhibition of ATPase function, indicating the potential for using URS in combination with detergents or ATPase inhibitors to treat MRSA infections.

Understanding the fine ultrastructure of the bacterial cell wall is important to gain insight into bacterial physiology and the mechanism of action of antibiotics against bacteria (40). Using TEM to observe morphological changes in bacterial cells provides useful insights into the mechanism underlying the activity of antibacterial agents (41). When bacteria cells were treated with URS and OXA, cell membrane disintegration, cell lysis, and release of cytoplasmic contents were observed (Fig. 4D) and the ultrastructure impact on bacteria cells indicated URS had antibacterial effects and was synergistic with OXA.

OXA is a $\beta$-lactam antibiotic that inhibits cell wall peptidoglycans through binding and competitive inhibition with PBPs (42). S. aureus antibiotic resistance was caused by $\mathrm{PBP} 2 \mathrm{a}$ production, which is a protein that binds to $\beta$-lactam antibiotics with lower affinity (10). PBP2a blocked the effects and replaced the function of normal PBPs. Therefore, the inhibition of PBP2a expression is an effective approach to restore the susceptibility of MRSA to antibiotics. In the present study, 
the protein expression of PBP2a was suppressed compared to the control when samples were treated with the combination of URS and OXA, but the presence of the band indicated that PBP2a expression was not completely inhibited (Fig. 5). Resistance to the $\beta$-lactam antibiotics, including OXA, is primarily mediated by $\mathrm{PBP} 2 \mathrm{a}$ production encoded by the $m e c A$ gene (43). The results indicated an antimicrobial effect of URS owing to an effect on PBP 2 a protein levels and the further study of RNA levels is needed.

In this study, URS, isolated from the leaves of $A$. henryi (Oliv.) Harms, is a plant-based antimicrobial agent that was found to be effective against MRSA and MSSA. In addition, the authors demonstrated the synergistic effect and mechanism of action of URS combined with OXA in the treatment against MRSA. Combination treatment indicated that URS had potential as a novel antibacterial agent for antimicrobial therapy of infections caused by MRSA. Notwithstanding the results obtained in the present study proved the antimicrobial activity of URS in vitro, a limitation of this study is the fact that we need further confirm the antibacterial activity of URS in vivo, and more experiments will be carried out in subsequent studies. S.aureus secretes a wide range of virulence factors and $\alpha$-hemolysin plays an important role in the induction of lung injury infected by $S$. aureus pneumonia (44). Staphylococcal enterotoxins are the virulence factors result in gastroenteritis, which also cause the food poisoning in human (45). Further studies will include the influence of URS on staphylococcal $\alpha$-hemolysin and enterotoxin productions.

\section{Acknowledgements}

This study was supported by the Basic Science Research Program through the National ResearchFoundation(NRF) of Koreafunded by the Ministry of Education (NRF-2016R1D1A1B03934552). Following are results of a study on the 'Leaders in IndustryUniversity Cooperation' Project, supported by the Ministry of Education and National Research Foundation of Korea.

\section{References}

1. Jiang JH and Peleg AY: Daptomycin-nonsusceptible Staphylococcus aureus: The role of combination therapy with daptomycin and gentamicin. Genes (Basel) 6: 1256-1267, 2015.

2. Mahdiyoun SM, Kazemian H, Ahanjan M, Houri H and Goudarzi M: Frequency of aminoglycoside-resistance genes in methicillin-resistant Staphylococcus aureus (MRSA) isolates from hospitalized patients. Jundishapur J Microbiol 9: e35052, 2016.

3. Hu Y, Liu A, Vaudrey J, Vaiciunaite B, Moigboi C, McTavish SM, Kearns A and Coates A: Combinations of $\beta$-lactam or aminoglycoside antibiotics with plectasin are synergistic against methicillin-sensitive and methicillin-resistant Staphylococcus aureus. PLoS One 10: $\mathrm{e} 0117664,2015$.

4. Ekambaram SP, Perumal SS, Balakrishnan A, Marappan N, Gajendran SS and Viswanathan V: Antibacterial synergy between rosmarinic acid and antibiotics against methicillinresistant Staphylococcus aureus. J Intercult Ethnopharmacol 5: 358-363, 2016.

5. Poulsen MØ, Jacobsen K, Thorsing M, Kristensen NR, Clasen J, Lillebæk EM, Skov MN, Kallipolitis BH, Kolmos HJ and Klitgaard JK: Thioridazine potentiates the effect of a beta-lactam antibiotic against Staphylococcus aureus independently of mecA expression. Res Microbiol 164: 181-188, 2013.

6. McConeghy KW, Bleasdale SC and Rodvold KA: The empirical combination of vancomycin and a $\beta$-lactam for Staphylococcal bacteremia. Clin Infect Dis 57: 1760-1765, 2013.
7. Lee YS, Lee DY, Kim YB, Lee SW, Cha SW, Park HW, Kim GS, Kwon DY, Lee MH and Han SH: The mechanism underlying the antibacterial activity of Shikonin against methicillin-resistant Staphylococcus aureus. Evid Based Complement Alternat Med 2015: 520578, 2015.

8. Lowy FD: Antimicrobial resistance: The example of Staphylococcus aureus. J Clin Invest 111: 1265-1273, 2003.

9. Tenover FC: Mechanisms of antimicrobial resistance in bacteria. Am J Med 119 (Suppl 1): S3-S70, 2006.

10. Ike B, Ugwu MC, Ikegbunam MN, Nwobodo D, Ejikeugwu C, Gugu T and Esimone CO: Prevalence, antibiogram and molecular characterization of comunity-acquired methicillin-resistant Staphylococcus Aureus in AWKA, Anambra Nigeria. Open Microbiol J 10: 211-221, 2016.

11. Santiago C, Pang EL, Lim KH, Loh HS and Ting KN: Reversal of ampicillin resistance in MRSA via inhibition of penicillinbinding protein $2 \mathrm{a}$ by Acalypha wilkesiana. BioMed Res Int 2014: 965348, 2014.

12. Park SY, Yook CS, Nohara T, Mizutani T and Tanaka T: Random amplified polymorphic DNA analysis of genetic relationships among Acanthopanax species. Arch Pharm Res 27: 1270-1274, 2004.

13. Park SY: Studies on RAPD analysis and triterpenoidal constituents of Acanthopanax species. Kumamoto University Press 3: 1-3, 2002.

14. Zhang XD, Liu XQ, Kim YH and Whang WK: Chemical constituents and their acetyl cholinesterase inhibitory and antioxidant activities from leaves of Acanthopanax henryi: Potential complementary source against Alzheimer's disease. Arch Pharm Res 37: 606-616, 2014.

15. Kim JH, Liu XQ, Dai L, Yook CS and Lee KT: Cytotoxicity and anti-inflammatory effects of root bark extracts of Acanthopanax henryi. Chin J Nat Med 12: 121-125, 2014.

16. Grace G, Paulo SE and Seligmann O: A new saponin from mate, Ilex paraguariensis. J Nat Prod 52: 1367-1370, 1989.

17. Li Z: Simultaneous determination of fifteen triterpenoid saponins in different medicinal parts of Acanthopanax henryi by HPLC CAD ESI MS. In: Study on chemical constituents of Acanthopanax henryi (Oliv.) Harms. Hunan University of Traditional Chinese Medicine, pp45-66, 2015.

18. Joung DK, Kang OH, Seo YS, Zhou T, Lee YS, Han SH, Mun SH, Kong R, Song HJ, Shin DW, et al: Luteolin potentiates the effects of aminoglycoside and $\beta$-lactam antibiotics against methicillin-resistant Staphylococcus aureus in vitro. Exp Ther Med 11: 2597-2601, 2016.

19. Joung DK, Mun SH, Choi SH, Kang OH, Kim SB, Lee YS, Zhou T, Kong R, Choi JG, Shin DW, et al: Antibacterial activity of oxyresveratrol against methicillin-resistant Staphylococcus aureus and its mechanism. Exp Ther Med 12: 1579-1584, 2016.

20. Shi YJ, Chen J and Xu M: A new method for antimicrobial susceptibility testing of in vitro-cultured bacteria by means of resonance light scattering technique. J Microbiol Biotechnol 18: $118-123,2008$.

21. Timurkaynak F, Can F, Azap ÖK, Demirbilek M, Arslan H and Karaman SÖ: In vitro activities of non-traditional antimicrobials alone or in combination against multidrug-resistant strains of Pseudomonas aeruginosa and Acinetobacter baumannii isolated from intensive care units. Int J Antimicrob Agents 27: 224-228, 2006.

22. Mun SH, Kang OH, Joung DK, Kim SB, Seo YS, Choi JG, Lee YS, Cha SW, Ahn YS, Han SH, et al: Combination therapy of Sophoraflavanone B against MRSA: In vitro synergy testing. Evid Based Complement Altern Med 2013: 823794, 2013.

23. Choi JG, Kang OH, Brice OO, Lee YS, Chae HS, Oh YC, Sohn DH, Park H, Choi HG, Kim SG, et al: Antibacterial activity of Ecklonia cava against methicillin-resistant Staphylococcus aureus and Salmonella spp. Foodborne Pathog Dis 7: 435-441, 2010.

24. Farooqui A, Khan A, Borghetto I, Kazmi SU, Rubino S and Paglietti B: Synergistic antimicrobial activity of Camellia sinensis and Juglans regia against multidrug-resistant bacteria. PLoS One 10: e0118431, 2015.

25. Cordwell SJ, Larsen MR, Cole RT and Walsh BJ: Comparative proteomics of Staphylococcus aureus and the response of methicillin-resistant and methicillin-sensitive strains to Triton X-100. Microbiology 148: 2765-2781, 2002.

26. Shibata H, Saito H, Yomota C, Kawanishi T and Okuda H: Alterations in the detergent-induced membrane permeability and solubilization of saturated phosphatidylcholine/cholesterol liposomes: Effects of poly(ethylene glycol)-conjugated lipid. Chem Pharm Bull (Tokyo) 60: 1105-1111, 2012. 
27. Linnett PE and Beechey RB: Inhibitors of the ATP synthethase system. Methods Enzymol 55: 472-518, 1979.

28. Mun SH, Kim SB, Kong R, Choi JG, Kim YC, Shin DW, Kang $\mathrm{OH}$ and Kwon DY: Curcumin reverse methicillin resistance in Staphylococcus aureus. Molecules 19: 18283-18295, 2014.

29. Hartmann M, Berditsch M, Hawecker J, Ardakani MF, Gerthsen D and Ulrich AS: Damage of the bacterial cell envelope by antimicrobial peptides gramicidin S and PGLa as revealed by transmission and scanning electron microscopy. Antimicrob Agents Chemother 54: 3132-3142, 2010.

30. Sambrook J and Russell DW: Molecular Cloning: A Laboratory Manual. 2nd edition. Cold Spring Harbor Laboratory Press, New York, NY, 1989.

31. Eom SH, Kang SK, Lee DS, Myeong JI, Lee J, Kim HW, Kim KH, Je JY, Jung WK and Kim YM: Synergistic antibacterial effect and antibacterial action mode of chitosan-ferulic acid conjugate against methicillin-resistant Staphylococcus aureus. J Microbiol Biotechnol 26: 784-789, 2016.

32. Klitgaard JK, Skov MN, Kallipolitis BH and Kolmos HJ: Reversal of methicillin resistance in Staphylococcus aureus by thioridazine. J Antimicrob Chemother 62: 1215-1221, 2008.

33. Eom SH, Lee DS, Jung YJ, Park JH, Choi JI, Yim MJ, Jeon JM, Kim HW, Son KT, Je JY, et al: The mechanism of antibacterial activity of phlorofucofuroeckol-A against methicillin-resistant Staphylococcus aureus. Appl Microbiol Biotechnol 98 : 9795-9804, 2014.

34. Irvin RT, MacAlister TJ and Costerton JW: Tris(hydroxymethyl) aminomethane buffer modification of Escherichia coli outer membrane permeability. J Bacteriol 145: 1397-1403, 1981

35. Joung DK, Joung H, Yang DW, Kwon DY, Choi JG, Woo S, Shin DY, Kweon OH, Kweon KT and Shin DW: Synergistic effect of rhein in combination with ampicillin or oxacillin against methicillin-resistant Staphylococcus aureus. Exp Ther Med 3: 608-612, 2012.

36. Ba X, Harrison EM, Lovering AL, Gleadall N, Zadoks R, Parkhill J, Peacock SJ, Holden MT, Paterson GK and Holmes MA: Old drugs to treat resistant bugs: Methicillinresistant Staphylococcus aureus isolates with mecC are susceptible to a combination of penicillin and clavulanic acid. Antimicrob Agents Chemother 59: 7396-7404, 2015.

37. Choi JG, Choi JY, Mun SH, Kang OH, Bharaj P, Shin DW, Chong MS and Kwon DY: Antimicrobial activity and synergism of Sami-Hyanglyun-Hwan with ciprofloxacin against methicillin-resistant Staphylococcus aureus. Asian Pac J Trop Med 8: 538-542, 2015
38. Mot YY, Othman I and Sharifah SH: Synergistic antibacterial effect of co-administering adipose-derived mesenchymal stromal cells and Ophiophagus hannah L-amino acid oxidase in a mouse model of methicillin-resistant Staphylococcus aureus-infected wounds. Stem Cell Res Ther 8: 5, 2017.

39. Rolfe MD, Rice CJ, Lucchini S, Pin C, Thompson A, Cameron AD, Alston M, Stringer MF, Betts RP, Baranyi J, et al: Lag phase is a distinct growth phase that prepares bacteria for exponential growth and involves transient metal accumulation. J Bacteriol 194: 686-701, 2012.

40. Alharbi NS, Khaled JM, Alzaharni KE, Mothana RA, Alsaid MS, Alhoshan M, Dass LA, Kadaikunnan S and Alobaidi AS: Effects of Piper cubeba L. essential oil on methicillin-resistant Staphylococcus aureus: An AFM and TEM study. J Mol Recognit 30: 1-8, 2017.

41. Joung DK, Mun SH, Lee KS, Kang OH, Choi JG, Kim SB, Gong R, Chong MS, Kim YC, Lee DS, et al: The antibacterial assay of tectorigenin with detergents or ATPase inhibitors against methicillin-resistant Staphylococcus aureus. Evid Based Complement Alternat Med 2014: 716509, 2014.

42. Carvalho JF, Azevedo ÍM, Rocha KB, Medeiros AC and Carriço AD: Oxacillin magnetically targeted for the treatment of methicillin-resistant S. aureus infection in rats. Acta Cir Bras 32: 46-55, 2017.

43. Hong SB, Rhee MH, Yun BS, Lim YH, Song HG and Shin KS: Synergistic anti-bacterial effects of Phellinus baumii ethyl acetate extracts and $\beta$-lactam antimicrobial agents against methicillin-resistant Staphylococcus aureus. Ann Lab Med 36: 111-116, 2016.

44. Dong J, Qiu J, Wang J, Li H, Dai X, Zhang Y, Wang X, Tan W, Niu X, Deng X, et al: Apigenin alleviates the symptoms of Staphylococcus aureus pneumonia by inhibiting the production of alpha-hemolysin. FEMS Microbiol Lett 338: 124-131, 2013.

45. Mun SH, Kong R, Seo YS, Zhou T, Kang OH, Shin DW and Kwon DY: Subinhibitory concentrations of punicalagin reduces expression of virulence-related exoproteins by Staphylococcus aureus. FEMS Microbiol Lett 363: 1-6, 2016. 